\title{
Studi Kunjungan Harian Arthropoda Pada Tanaman Ageratum Conyzoides dan Synedrella Nodiflora di Area Pertanian Desa Wringinpitu Kecamatan Mojowarno Sebagai Bahan Pengembangan E-Katalog
}

\author{
Ana Fitria ${ }^{1 *}$, Nora Iffatul Maula Ahmad' \\ Universitas KH. A. Wahab Hasbullah, Jombang, Indonesia \\ "Corresponding author: anazahrah13@gmail.com
}

\begin{abstract}
Abstrak: Refugia merupakan tanaman yang dapat menarik dan mengundang sejumlah musuh alami seperti hama, pretador dan parasitoid. Selain itu, refugia juga membantu para petani untuk melindungi sawahnya seperti tanaman padi, jagung dan lain-lain. Dengan adanya tumbuhan liar atau tanaman refugia sebagai bentuk pelestarian Artrhopoda agar ekosistem tetap terjaga dan seimbang. Penelitian ini bertujuan untuk mengetahui frekuensi dan distribusi temporal kunjungan harian Arthropoda pada tanaman Ageratum Conyzoides dan Synedrella Nodiflora hasilnya dari penelitian tersebut akan digunakan sebagai bahan pengembangan e-katalog. Penelitian dilakukan di area pertanian Desa Wringinpitu Kecamatan Mojowarno Kabupaten Jombang. Metode yang digunakan dalam penelitian ini adalah metode visual control dengan pengamatan dilakukan secara $3 x$ ulangan. Hasil penelitian ini menunjukkan adanya perbedaan frekuensi dan ditribusi temporal kunjungan Arthropoda terhadapan tanaman Ageratum Conyzoides dan Synedrella Nodiflora. Pada tumbuhan liar Ageratum Conyzoides dikunjungi oleh 8 family Arthropoda sedangan tumbuhan liar Synedrella Nodiflora hanya dikunjungi 6 family Arthropoda. Hasil dari kegiatan pengamatan ini akan dibuat sebagai pengembangan bahan ajar e-katalog untuk memudahkan peserta didik agar dapat mengenal dan mempelajari tentang hewan Artrhopoda yang ada di area pertanian. Agar mendapatkan kelayakan dalam buku sampingan peserta didik ini, perlu divalidasi oleh ahli materi dan peserta didik dengan aspek-aspek yang dinilai mengguunakan skala likert kemudian dianalisis dan diperoleh tingkat pencapaian sebesar 80 \% yang artinya layak digunakan.
\end{abstract}

Kata Kunci: Frekuensi Kunjungan Karian, Faktor Abiotik, Distribusi Temporal, Arthropoda, Ageratum Conyzoides dan Synedrella Nodiflora

Abstract: Refugia is a plant that can attract and invite a number of natural enemies such as pests, predators and parasitoids. In addition, refugia also helps farmers to protect their fields such as rice, corn and others. With the presence of wild plants or refugia plants as a form of Arthropod conservation so that the ecosystem is maintained and balanced. This study aims to determine the frequency and temporal distribution of daily Arthropoda visits on Ageratum Conyzoides and Synedrella Nodiflora plants. The results of this study will be used as material for developing e-catalogs. The research was conducted in the agricultural area of Wringinpitu Village, Mojowarno District, Jombang Regency. The method used in this study was a visual control method with observations carried out 3 times. The results of this study indicate that there are differences in the frequency and temporal distribution of Arthropoda visits to Ageratum Conyzoides and Synedrella Nodiflora plants. The wild plants of Ageratum Conyzoides were visited by 8 Arthropoda families while the Synedrella Nodiflora wild plants were only visited by 6 Arthropoda families. The results of this observation activity will be made as the development of e-catalog teaching materials to make it easier for students to recognize and learn about Arthropod animals in agricultural areas. In order to get the feasibility of this student side book, it needs to be validated by material experts and students with aspects assessed using a Likert scale then analyzed and obtained an achievement rate of $80 \%$ which means it is feasible to use.

Keywords: Frequency of Carian Visits, Abiotic Factors, Temporal Distribution, Arthropods, Ageratum 


\section{PENDAHULUAN}

Refugia dapat menyediakan tempat berlindung secara spasial dan/atau temporal bagi musuh alami hama seperti predator dan parasitoid, serta mendukung komponen interaksi biotik pada ekosistem seperti pollinator (llhamiyah dkk. 2020). Berbagai jenis dari hama tergolong dalam filum Arthropoda. Pelestarian Arthropoda agar ekosistem tetap seimbang, terjaga dan sebagai bentuk pengendalian hama secara alami tanpa menggunakan pestisida pada tanaman padi dengan adanya tumbuhan - tumbuhan liar diarea pertanian.

Di Indonesia wilayah yang telah memanfaatkan tumbuhan liar atau tanaman refugia adalah Desa Wringinpitu Kecamatan Mojowarno salah satu diantaranya tanaman Ageratum Conyzoides dan Synedrella Nodiflora. Tumbuhan liar mampu menarik Arthropoda sebagai pemanfaatan habitatnya. Arthropoda memiliki distribusi temporal yang berbeda-beda. Ritme pada serangga disebut dengan jam biologis (biological clock) (Purwanti, 2011). Distribusi temporal Arthropoda dapat digunakan sebagai dasar kapan dilaksanakannya pangendalian hama terpadu (PHT). Melalui biological clock ada kemungkinan untuk menentukan aktifitas-aktifitas yang dilakukan oleh Arthropoda maka perlu dilakukan penelitian Studi Kunjungan Harian Arthropoda Pada Tanaman Ageratum Conyzoides Dan Synedrella Nodiflora agar dapat mengetahui bagaimana dan kapan Arthropoda mengunjungi tanaman refugia. Hasil dari penelitian tersebut akan dijadikan bahan untuk pengembangan bahan ajar yang berupa e-katalog.

\section{METODE PENELITIAN}

Penlitian dilakukan di Desa Winginpitu Kecamatan Mojowarno Kabupaten Jombang, dilaksanakan pada bulan Juli 2021. Populasi penelitian adalah semua populasi Arthropoda di area Desa Wringinpitu. Sedangkan sampel dalam penelitian adalah semua Arthropoda yang teramati pada tanaman terpilih yaitu Ageratum Conyzoides dan Synedrella Nodiflora. Alat yang digunakan untuk penelitian ini adalah kamera handpone, alat tulis dan lup. Sebagai penunjang dalam penelitian ini adalah jurnal-jurnal ilmiah tentang arthropoda dan tanaman refugia.

Sebelum melakukan pengamatan adalah survey lapangan untuk menentukan tanaman refugianya, melakukan latihan pengamatan menggunakan metode visual control dan simulasi penangkapan serta mengidentifikasi jenis arthropoda. Penentuan tumbuhan amatan menggunakan metode jelajah dengan menentukan 1 petak tanaman Ageratum Conyzoides dan Synedrella Nodiflora.

Metode yang digunakan dalam pengamatan adalah modifikasi metode "visual control" yang dikembangkan oleh Frei dan Manhart (1992). Metode visual control adalah metode pengamatan jarak jauh antara tumbuhan amatan dan pengamat sejauh 2 Meter dan dilakukan dalam waktu tertentu dengan mengamati secara langsung serangga yang mengunjungi tanaman refugia.

Arthropoda diamati sebanyak $3 x$ ulangan pada masing-masing jenis tanaman refugia dengan pengambilan data yang dilakukan pada pukul 06.00-07.00 dan 16.00-15.00 di pagi dan sore hari. Ulangan yang dilakukan adalah hari dan selanjutnya mencatat data yang diamati. Analisis data dilakukan dengan menggunakan metode statistik deskriptif (Dora, D.R.T. dkk. 2011).

Data yang terkait dengan komposisi dan frekuensi kunjungan harian Arthropoda pada tumbuhan liar Ageratum Conyzoides dan Synedrella Nodiflora dilakukan analisis statistik dengan metode uji t dengan taraf signifikansi 5\%. Data yang terkait dengan distribusi temporal frekuensi kunjungan harian Arthropoda pada tumbuhan liar Ageratum Conyzoides dan Synedrella Nodiflora disajikan dalam bentuk diagram kemudian diintepretasikan secara deskriptif.

\section{HASIL DAN PEMBAHASAN}

Distribusi temporal Arthropoda memiliki hasil yang berbeda sehingga frekuensi kunjungan harian Artrhopoda pada tumbuhan liar Ageratum Conyzoides dan Synedrella Nodiflora mengalami fluktuasi disetiap waktu. Diantara anggota filum Arthropoda diketahui ada yang 
sangat berguna bagi kehidupan manusia dan sebaliknya diketahui pula ada yang berperan merugikan manusia dan hewan. Kelompok yang terakhir ini lebih dikenal sebagai ektoparasit atau pengganggu atau hama. Yang termasuk di dalam kelompok ektoparasit adalah kelas Insecta (serangga) dan kelas Arachnida (caplak dan tungau) (Upik, K.H. 2010). Berikut adalah macammacam Arthropoda yang mengunjungi tumbuhan liar Ageratum Conyzoides dan Synedrella Nodiflora.

Tabel 1. Macam-macam Artrhopoda yang mengunjungi tumbuhan liar Ageratum Conyzoides dan Synedrella Nodiflora

\begin{tabular}{cc}
\hline Tanaman Refugia & Nama Family Arthropoda \\
\hline Ageratum Conyzoides & Coccinellidae \\
& Carabidae \\
& Tephritidae \\
Acrididae & Papilionidae \\
& Tetranychidae \\
Formicidae & Syrhipidae \\
& Oxyopidae \\
\hline & Formicidae \\
& Gryllidae \\
& Oxyopidae \\
& Acrididae \\
& Carabidae \\
& Tetranychidae \\
\hline
\end{tabular}

Berdasarkan tablel 1 pada liar Ageratum Conyzoides dan Synedrella Nodiflora mampu menarik beberapa Arthropoda dalam 3 hari penelitian, setiap waktu penelitian Arthropoda yang mengunjungi tumbuhan liar tersebut mengalami fluktuasi. Adapun hasil dari penelitian pada Ageratum Conyzoides dan Synedrella Nodiflora sebagai berikut:

A. Hasil Penelitian Kunjungan Arthropoda Pada Tumbuhan Ageratum Conyzoides

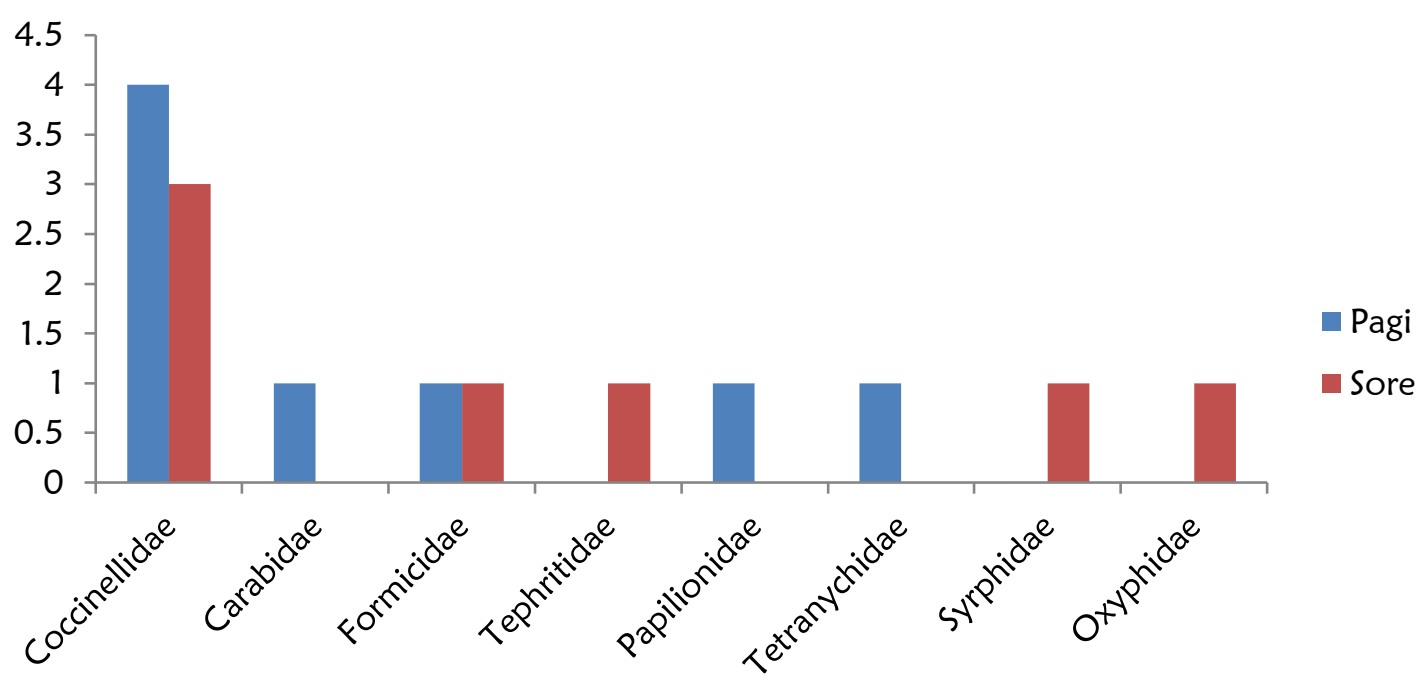

Gambar 1. Grafik Kunjungan family Arthropoda pada tumbuhan Ageratum Conyzoides

Berdasarkan Gambar 1, hasil yang didapat dari pengambilan data pada tumbuhan Ageratum Conyzoides bertempat diarea pertanian Desa Wringinpitu pada pagi hari adalah 4 ekor Coccinellidae, 1 ekor Carabidae, 1 ekor Formicidae, 1 ekor Papilionidae, dan 1 ekor Tetranichidae. Sedangkan pada sore hari terdapat 3 ekor Coccinellidae, 1 ekor Formicidae, 1 ekor Tephritidae, 1 ekor Sryphidae, 1 ekor Oxyphidae. Family yang memiliki frekuensi tertinggi adalah Coccinellidae baik di pagi hari ada 4 ekor dan sore hari ada 3 ekor. 
B. Hasil Penelitian Kunjungan Arthropoda Pada Tumbuhan Synedrella Nodiflora

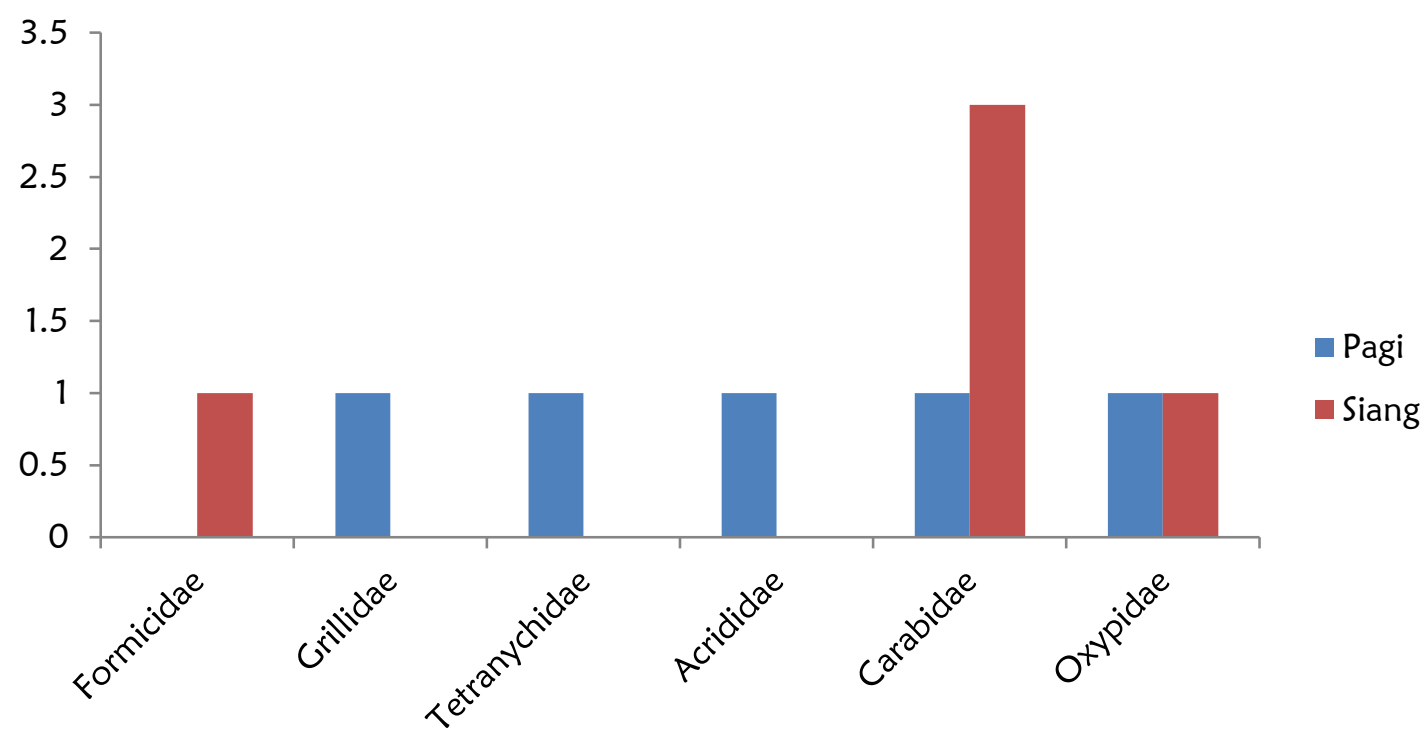

Gambar 2. Grafik Kunjungan family Arthropoda pada tumbuhan Synedrella Nodiflora

Berdasarkan Gambar 2, hasil yang didapat dari pengambilan data pada tumbuhan Synedrella Nodiflora bertempat diarea pertanian Desa Wringinpitu pada pagi hari adalah 1 ekor Grillidae, 1 ekor Tetranychidae, 1 ekor Acrididae, 1 ekor carabidae, 1 ekor oxypidae. Sedangkan pada sore hari terdapat ekor Formicidae, 3 ekor carabidae, 1 ekor oxypidae. Family yang memiliki frekuensi tertinggi adalah Carabidae 3 ekor di sore sedangkan frekuensi dipagi hari sama-sama mendapatkan 1 ekor Athropoda.

\section{Distribusi Temporal pada tumbuhan Ageratum Conyzoides dan Synedrella Nodiflora}

Berdasarkan data waktu yang diperoleh pada penelitian Family Arthropoda yang ditemukan rentang waktu paling banyak yaitu di pagi hari hal ini berkaitan dengan jam biologi (biological clock) disetiap arthropoda memiliki waktu yang berbeda. Berdasarkan penelitian yang dilakukan oleh Muhamammad, R.y. dkk (2020) pengaruh banyak atau sedikitnya Artrhopoda yang dating yaitu berupa pengaruh faktor abiotik berupa intensitas cahaya, Serangga diurnal merupakan serangga yang membutuhkan intensitas cahaya tinggi, sehingga aktif pada siang hari dan tidak aktif pada malam hari. Faktor Abiotik lainnya seperti suhu dan kelembapan, dimana serangga memiliki kisaran suhu tertentu dimana serangga dapat hidup, di luar kisaran suhu tersebut serangga akan kedinginan atau kepanasan sehingga menyebabkan kematian. Pengaruh suhu ini jelas terlihat pada proses fisiologi serangga. Suhu tertentu aktivitas serangga tinggi, akan tetapi pada suhu yang lain akan berkurang (menurun).

D. Implikasi studi kunjungan harian arthropoda pada tanaman Ageratum Conyzoides dan Synedrella Nodiflora sebagai bahan ajar pengembangan e-katalog

Hasil dari penelitian dalam pengembangan bahan ajar telah disusun menjadi e-katalog berisi jenis-jenis Artrhopoda yang ditemukan pada tanaman Ageratum Conyzoides dan Synedrella Nodiflora sesuai hasil dari penelitian yang dilakukan diarea pertanian Desa Wringinpitu Kecamatan Mojowarno. Bahan ajar e-katalog ini divalidasi oleh ahli materi dan peserta didik dengan aspek-aspek yang dinilai mengguunakan skala likert kemudian dianalisis dan diperoleh tingkat pencapaian sebesar $80 \%$ yang artinya layak digunakan.

Harapan dengan dikembangkan bahan ajar berbasis e-katalog ini dapat memudahkan peserta didik dalam mempelajari dan mengenal tentang Artrhopoda pada tanaman refugia diarea pertanian. Tidak hanya itu adanya e-katalog ini dapat mendatangkan suatu inovasi dalam belajar peserta didik guna meningkatkan motivasinya dalam mempelajari ilmu biologi. 


\section{KESIMPULAN}

Berdasarkan hasil dari penelitian dapat disimpulkan bahwa tanaman Ageratum Conyzoides dikunjungi oleh 8 Family Arthropoda sedangan tanaman Synedrella Nodiflora dikunjungi 6 Family Arthropoda. Distribusi temporal yang dimiliki oleh Arthropoda ada kaitanya dengan jam bilogis (biological clock) sehingga mengetahui adanya waktu istirahat dan aktifitas yang dilakukan Arthropoda. Dari beberapa penemuan Arthropoda pada tanaman refugia akan disusun menjadi pengembangan bahan ajar e-katalog sebagai penunjang belajar peserta didik dalam mempelajari ilmu biologi khususnya untuk mengenal dan memahami hewan Arthropoda pada tanaman refugia diarea pertanian.

\section{DAFTAR PUSTAKA}

Dora, D. R. T., Rohman, F., Yanuwiadi, B. (2011) Studi kunjungan harian Arthropoda pada tumbuhan liar Centella asiatica L. Dan synedrella nodiflora (L) di area kebun the Wonosari singosari kabupaten malang.

Ilhamiyah, Gusti, K. N., Zuraida, A., Widaningsih, N., (2020) Sosialisasi dan pemanfaatan tanaman refugia sebagai alternatif pengendali hama tanaman. Jurnal Pengabdian Al-Ikhlas. ISSN: 2461-0992

Muhammad, R. Y., Siti, A. K., Nadya, R. N. R., Intan, A. I. W., (2020) Distribusi temporal dan spatial arthropoda pada berbagai jenis tumbuhan liar di agroekosistem. Jurnal Bionature. eISSN 2654-5160 p-ISSN 1411-4720

Purwanti, Dewi. 2011. Perilaku Serangga. Jatinangor: Jurusan Biologi Universitas Padjadjaran. 